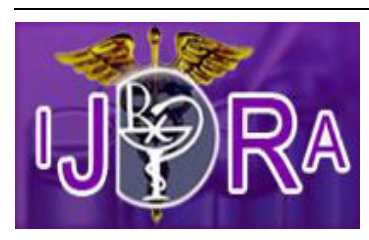

Available online on 15 June 2018 at http://ijdra.com/index.php/journal

International Journal of Drug Regulatory Affairs

Open Access to Pharmaceutical and Medical Research

() 2013-18, Publisher and Licensee IJDRA.

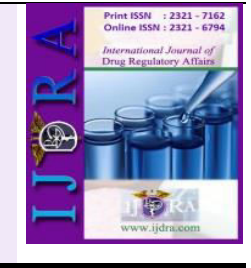

Review Article

Open

Access

\title{
A Comprehensive and Comparative study of qualification process for Drug Development tools in US, Europe, Japan and India.
}

\author{
Garima Kshatriya*, Dilip G. Maheshwari \\ Department of Quality Assurance and Pharm Regulatory Affairs-LJIP-Ahmedabad, Gujarat, .India.
}

\begin{abstract}
Drug Development Tools are methods, materials, or measures that have the potential to facilitate drug development. USFDA has specified three major drug development tools and has also given the guidelines recommending their qualification which would expedite the drug development process. This qualification would ensure better understanding of drug targets and long term safety outcomes. Regulatory authorities of Europe, Japan \& India have also focused on developing a formal qualification process of drug development tools though most of it follows USFDA.
\end{abstract}

Keywords: Drug Development Tools, Qualification, Regulations, Context of Use, Biomarkers, Clinical Outcome Assessment, Animal Models.

Article Info: Received 21 March 2018; Review Completed 30 April 2018; Accepted 03 June 2018

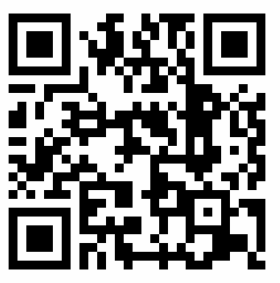

Cite this article as:

Kshatriya G, Maheshwari D. A Comprehensive and Comparative study of qualification process for Drug Development tools in US, Europe, Japan and India. International Journal of Drug Regulatory Affairs [Internet] 15 Jun.2018 [cited 15 Jun. 2018]; 6(2):1-7. Available from: http://ijdra.com/index.php/journal/article/view/227

DOI:10.22270/ijdra.v6i2.227

*Corresponding author. Tel.: +91-8460265728;

E-mail address: garimakshatriya17@gmail.com (G. Khsatriya).

\section{Introduction}

Qualification is a conclusion that within the stated COU (context of use), the DDT can be relied on to have a specific interpretation and application in drug development and regulatory review. The COU describes the way the DDT is to be used and the purpose of the use. A complete COU statement should describe fully the circumstances under which the DDT is qualified and the boundaries within which the available data adequately support use of the DDT.

The DDT may have other potential value. For example, subject to review and discussion with CDER staff, DDT may be used in IND programs for a purpose outside of the qualified COU. A formal qualification process also creates advantages for FDA. Previously, if multiple sponsors were interested in using particular DDT, or one sponsor was interested in using DDT in multiple different clinical settings, FDA staff would have to perform multiple evaluations of the data to justify the DDT use on a case-by-case basis (1).
If instead, a formal qualification is achieved under the principles described in this guidance, the relevant data will need to be reviewed only once. Three types of DDTs include: biomarkers, clinical outcome assessment and animal models for use beneath the Animal Rule.

Qualifying DDT has long reaching benefits, not only for DDT developers but also for patients, FDA \& scientific community as whole. Some of the key benefits include:

- Expanding Use in clinical trials across multiple clinical disorders, drugs or drug classes

- Decreased burden on regulatory agencies for detailed review

- Encouraging a collaborative setting for advancement of additional DDTs (1).

\subsection{Utilization of Drug Development Tools in Drug} Development Process 


\section{Discovery and Development}

Preclinical Research

Clinical Research

FDA Review

FDA Post-Market Safety Monitoring

\section{Regulations for Qualification Process of Drug Development tools in U.S (2-5)}

The guidance delineates the procedure for qualifying drug development tools proposed for potential use, in various drug development programs. This guidance gives a structure to the Center for Drug Evaluation and Research (CDER) proposing the DDT for qualification. It exhibits the data that, if be submitted will support capability of DDT and likewise shapes a mechanism for CDER's formal overview of the data that will in the long run qualify the DDT.

\subsection{Biomarkers}

"A biological marker or biomarker is a characteristic that is objectively measured and evaluated as an indicator of normal biologic processes, pathologic processes, or biological responses to a therapeutic intervention."

Biomarkers are qualified by the FDA so they can be utilized by drug designers without the need to re-assess their legitimacy. Be that as it may, the utilization of biomarkers in any drug-development program ought to be carefully considered in consultation with the FDA.

The FDA's biomarker capability process is separated into three consecutive stages, and movement through these stages is dependent upon positive feedback from the FDA.

\subsection{Stages of Biomarker Qualification}

There are 3 stages of qualifying biomarkers.

- Initiation stage : Submit a letter of intent (LOI) that includes a high-level description supporting the use of a biomarker within a proposed context of use to the FDA.

- Consultation and advice stage :Put together a comprehensive biomarker qualification briefing package and receive input from the FDA.

- Review stage: Submit a full qualification package to the FDA

Once a biomarker is qualified, the FDA will send a letter to submitter(s) informing them of their decision. If the biomarker is qualified, it will then be posted on the DDT public webpage for potential use in other drug development programs. Similar to COAs, once a biomarker is validated, it does not need to be re-evaluated for use within a specific COU.

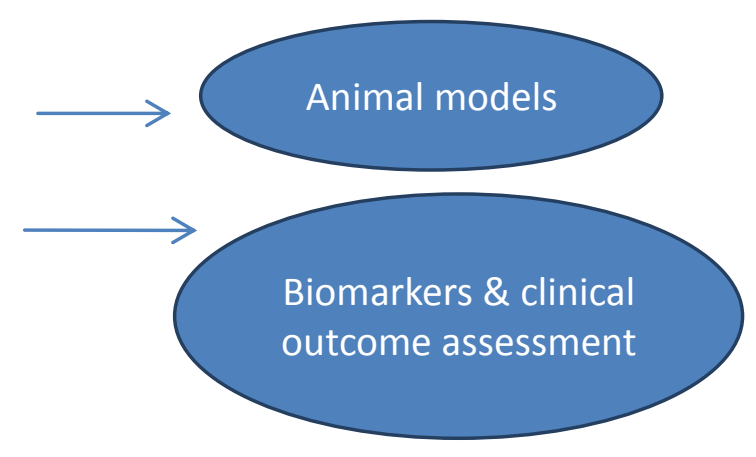

This does not mean that the FDA will necessarily accept these biomarkers in every clinical development program that cites the same COU, even though a biomarker is qualified, its inclusion in a drug-development program should be carefully considered in consultation with the FDA.

Biomarkers are commonly used in drug development as safety assessments to identify a toxic response in a patient, often before it becomes clinically evident. Biomarkers can also be used for patient selection for clinical study enrollment or for stratification of patients during study randomization.

\subsection{Clinical Outcome Assessment}

COAs are generated on a case by case basis and knowledge of their utilization is only made available to the public when the investigational drugs are used to evaluate or receive market approval. An integral part of the COA Qualification Program is its emphasis on ' transparency'.

In order to develop a COA, one should follow 6 general steps and get it qualified by FDA.

Step 1 - To Lay the groundwork

Step 2 - To Create the COA

Step $3 \& 4$ - To Test COA validity using a cross-sectional evaluation and submit to CDER

Step 5 \& 6 - To Examine COA \& make final submission to CDER

\subsection{Animal Model}

Qualification of an animal model through FDA's Animal Model Qualification Program (AMQP) is intentional (i.e., not required for product approval or licensure under the Animal Rule). The AMQP is together bolstered by CDER and CBER. The Committee on Animal Models for Assessing Counter measures to Bioterrorism Agents concludes that concentrating on the making of new animal models - that is, proceeding to depend only on the utilization of animals for efficacy studies - isn't justified as of now.

Albeit new models, for example, hamsters, New World nonhuman primates, pigs, or bats, might be valuable for essential research purposes, they will inevitably experience similar issues found in the better-characterized 
animal models as of now being used. Rather, the Committee recommends that it is more valuable to apply distinctive methodologies that "bolster the capability of animal models" and increase understanding of how animal data may more consistently predict the human response.

The Animal Model Qualification (AMQ) program applies specifically to animal models intended for use in the adequate and well-controlled efficacy studies that serve as substantial evidence of effectiveness for drugs developed under the Animal Rule. For qualification, the common history model ought to be practically equivalent to the human ailment [that is the sickness procedure or pathologic condition in a given types of animal compares in different essential perspectives to the human illness or state of interest.]

\section{Drug Development Qualification in "Europe" (6-10)}

\subsection{Qualification Process in Europe}

The EMA qualification process is scientific pathway leading to either CHMP qualification opinion on the acceptability of a specific use of the proposed method (e.g. use of a novel methodology or an imaging method) in a research and development (R\&D) context (nonclinical or clinical studies), based on the assessment of submitted data or CHMP qualification advice on future protocols and methods for further method development towards qualification, which is based on the evaluation of the scientific rationale and on preliminary data submitted.

\subsection{Biomarker}

The accessibility of techniques that encourage investigation of the human genome has prompted to an exponential increment in examination of concerning genomic biomarkers (GBMs) for determination of particular illnesses, as a marker of reaction to treatment. GBMs offer the advantage of enhanced specificity and lessening of heterogeneity that is an integral part of phenotypic populace grouping.

This is extremely appealing in drug development due to their potential capacity to decrease drug attrition and to reduce overall development costs that are accomplished through improved understanding of the mechanism of drug activity predict adverse events to individual drugs or as a group impact, and utilization of novel advancement methodologies in pre-clinical and clinical stages. In clinical drug development, GBMs may help and impact an extensive variety of regions: patient selection, stratification of treatment methodologies or patient groups, early assessment of treatment impact including antagonistic responses, and prognosis.

\subsection{Clinical Outcome Assessment}

The European Medicines Agency (EMA) has published new guidance on the use of patient-reported outcome (PRO) measures in oncology studies. This guidance document issued by the Committee for Medicinal Products for Human Use (CHMP) and its Oncology Working Party (ONCWP) describes the use of PROs and health related quality of life (HRQL) measures in clinical studies.
Patient-reported outcomes and quality of life measures

The experience of patients of how a treatment affects on their well-being and everyday life is an important aspect of the evaluation of the clinical benefits of new medicines. Patient Reported Outcomes includes any information directly reported by a patient that is based on his or her perception of a disease and its treatment. They provide data on a patient's quality of life, symptoms, treatment adherence or satisfaction with care.

\subsection{Essential points to carry out Clinical outcome assessment in Clinical Trial Design}

- General principles

- Frequency and duration of assessments

- Data collection and preventing avoidable missing data

\section{- Instruments}

\subsection{Animal model qualification}

The relevance of the selected animal model should be justified in the Clinical Trial application. The demonstration of relevance of the animal models may include comparison with humans of:

- Target expression, distribution and primary structure. However, a high degree of homology does not necessarily imply comparable effects;

- Pharmacodynamics

- Metabolism and other PK aspects;

- On- and off-target binding affinities and receptor/ligand occupancy and kinetics.

\section{Drug Development Tools Qualification in "Japan"}

\subsection{Regulations in Japan}

\section{Genomic Biomarkers}

Biomarkers (BM) are gradually being recognized as useful tools to evaluate drugs from development through post-approval periods. However, only two guidelines regarding BM, i.e., wordings of pharmacogenomics (E15 guideline) and document format in BM qualification submission to regulatory agencies (E16 guideline), have been harmonized in the ICH

The objective of the guideline is to create a harmonized structure for the qualification of genomic biomarkers that will foster consistency of applications across regions and expedite joint discussions with and among regulatory authorities. The format for a genomic biomarker submission recommended in this guideline can be applicable at any stage of drug discovery, development, or the post-approval period (11-12).

\subsection{Companion Diagnostics (CoDx)}

The identification of patient population to receive a certain therapeutic product by using a biomarker related to the target disease or condition would require utilization of an in vitro diagnostic ("IVD") before using that therapeutic product. An IVD that contributes to personalized medicine by being used in such settings as 
the selection of a therapeutic product is referred to as an "in vitro companion diagnostic" (11-12).

\subsection{Animal Models}

Animal experimentation and laboratory animals are legally defined within Japan. Animals used in lab testing should be bred, maintained and provided for various purposes, and regulations apply to all animals used in tests, from small rodents such as mice and rats, through cats, dogs, monkeys and birds. In accordance with the advancements in animal biotechnologies seen in recent years, there have been cases in which domestic livestock, such as pigs and cows, have been used in experimentation.
The ethics and principles behind the administrative structure for animal experimentation in Japan, as mentioned in Section 2-1, are stipulated in law (Law for the Humane Treatment and Management of Animals), and according to both the proclamation that specifies those regulations which refer specifically to 'animals' (Standards Relating to the Care and Management of Laboratory Animals and Relief of Pain) and the notification on 'experimentation' (regarding Animal Experiments in Universities etc.), each experimental facility is required to implement a system whereby it is responsible for regulating animal experimentation independently (11-12).

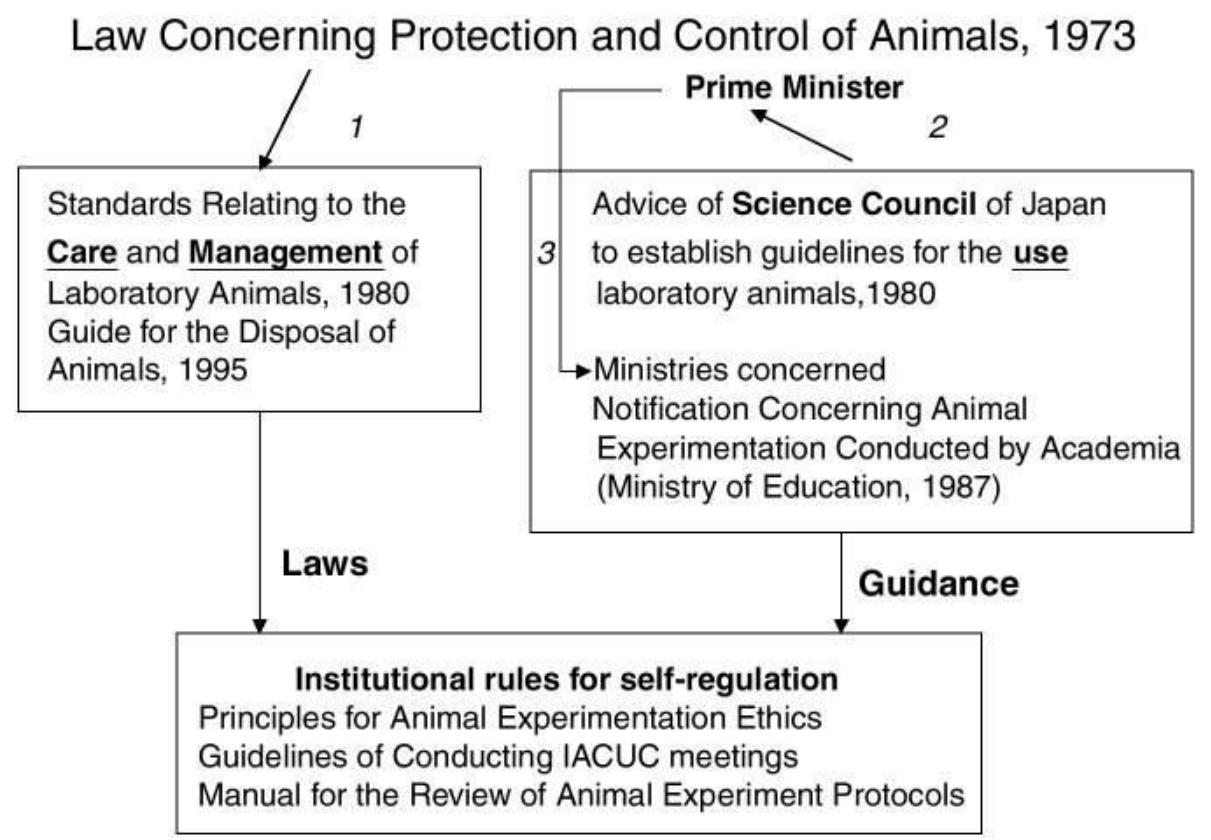

Figure 1. Law concerning protection and control of Animals, 1973

\section{Drug Development Tools in "India"}

\subsection{Regulations in India (16-18)}

\section{Biomarker}

In 2001, an NIH working group standardized the definition of a biomarker as "a characteristic that is objectively measured and evaluated as an indicator of normal biological processes, pathogenic processes, or pharmacologic responses to a therapeutic intervention" and defined types of biomarkers.

To explore the biomarkers that can be translated into clinical tests for screening, diagnosis, treatment and prognosis of the diseases and to understand the challenges which are involved in development, validation and incorporation of these markers, a collaborative ICMR INSERM workshop on "Development of Biomarkers for Cardiovascular Diseases and Diabetes" was held in Gurgaon, India from 22nd to 24th Jan 2007.

Identification of Genetic Markers in Indian Population: A Systematic Chaos
Genetic predisposition is one of the main risk factors to diabetes and cardiovascular disease. A huge effort to unravel this is being undertaken worldwide from over a decade but with little success. Identification of genetic markers in India has always been a systematic replication of the work done in other populations. Recent studies show that the most celebrated Ala12 allele of PPAR Pro12Ala polymorphism which is associated with lower risk of type 2 diabetes in various populations of world does not confer protection in Indian population.

\section{Animal Regulation}

Good Laboratory Practices (GLP) for animal facilities is intended to assure quality maintenance and safety of animals used in laboratory studies while conducting biomedical and behavioral research and testing of products. The goal of these Guidelines is to promote the humane care of animals used in biomedical and behavioral research and testing with the basic objective of providing specifications that will enhance animal well-being, quality in the pursuit of advancement of biological knowledge that is relevant to humans and animals. 


\section{India Passes New Rules to Protect Animals}

The Ministry of Environment, Forest and Climate Change has released four new Gazette notifications under the Prevention of Cruelty to Animals Act, 1960 to regulate dog breeders , animal markets, and aquarium and "pet" fish shop owners . This progress has come about as a joint effort by animal protection groups including PETA India. PETA India was involved in the public consultation process for these rules and had provided useful comment to strengthen protections.
The rules are the Prevention of Cruelty to Animals (Dog Breeding and Marketing) Rules, 2017;

Prevention of Cruelty to Animals (Regulation of Livestock Markets) Rules, 2017;

The Prevention of Cruelty to Animals (Aquarium and Fish Tank Animals Shop) Rules, 2017;

The Prevention of Cruelty to Animals (Care and Maintenance of Case Property Animals) Rules, 2017.

Table 1 Compare \& Contrast of the Regulatory difference between Qualification process of US, Europe, Japan \& India.

\begin{tabular}{|c|c|c|c|c|}
\hline $\begin{array}{c}\text { Qualification } \\
\text { Requirements }\end{array}$ & FDA & EMA & PMDA & CDSCO \\
\hline Procedure & $\begin{array}{l}3 \text { stages of } \\
\text { Qualification Process : } \\
\text { - Initiation } \\
\text { - Consultation and } \\
\text { Advice } \\
\text { - Review }\end{array}$ & $\begin{array}{l}3 \text { stages of } \\
\text { Qualification Process : } \\
\text { - Pre-submission } \\
\text { - Consultation and } \\
\text { advice by the secretariat } \\
\text { - Review by the } \\
\text { Scientific Advice } \\
\text { Working party }\end{array}$ & Not Mentioned & Not Mentioned \\
\hline Scope & $\begin{array}{l}\text { Drug Development } \\
\text { Tools for which there } \\
\text { are formal Qualif- } \\
\text { ication programs: } \\
\text { - Biomarkers } \\
\text { - Clinical Outcome } \\
\text { Assessments (patient- } \\
\text { reported outcomes, } \\
\text { clinician - reported } \\
\text { outcomes, observer- } \\
\text { reported outcomes and } \\
\text { Performance } \\
\text { Outcomes (PerfO)) } \\
\text { - Animal Models for } \\
\text { use under the FDA } \\
\text { Animal Rule }\end{array}$ & $\begin{array}{l}\text { Examples of novel } \\
\text { methodologies for } \\
\text { which there are formal } \\
\text { Qualification programs: } \\
\text { - Biomarkers } \\
\text { - Preclinical models } \\
\text { - Clinical Outcome } \\
\text { Assessments } \\
\text { - Modelling \& } \\
\text { statistical methods } \\
\text { - Any other novel } \\
\text { methodology, e.g. } \\
\text { imaging Although } \\
\text { scope is not formally } \\
\text { restricted }\end{array}$ & $\begin{array}{l}\text { Drug } \\
\text { Development } \\
\text { Tools: } \\
\text { - Biomarkers \& } \\
\text { Companion } \\
\text { Diagnostics } \\
\text { - Animal Models }\end{array}$ & $\begin{array}{l}\text { Drug } \\
\text { Development } \\
\text { Tools: } \\
\text { - Biomarkers } \\
\text { - Animal } \\
\text { Models }\end{array}$ \\
\hline Who can apply & $\begin{array}{l}\text { Submitter = person, } \\
\text { group, organisation } \\
\text { (including the federal } \\
\text { government), or } \\
\text { consortium that takes } \\
\text { responsibility for and } \\
\text { initiates a DDT } \\
\text { qualification proposal } \\
\text { using described } \\
\text { procedures }\end{array}$ & $\begin{array}{l}\text { Applicant = person, } \\
\text { group, organisation or } \\
\text { consortium; is } \\
\text { responsible for the fees } \\
\text { and initiates the process }\end{array}$ & $\begin{array}{l}\text { Applicant = } \\
\text { person, group, } \\
\text { organisation or } \\
\text { consortium; is } \\
\text { responsible for } \\
\text { the fees and } \\
\text { initiates the } \\
\text { process }\end{array}$ & $\begin{array}{l}\text { Applicant = } \\
\text { person, group, } \\
\text { organisation or } \\
\text { consortium; is } \\
\text { responsible for } \\
\text { the fees and } \\
\text { initiates the } \\
\text { process }\end{array}$ \\
\hline When to submit & $\begin{array}{l}\text { As early as possible to } \\
\text { obtain prospective } \\
\text { advice }\end{array}$ & $\begin{array}{l}\text { As early as possible to } \\
\text { obtain prospective } \\
\text { advice }\end{array}$ & $\begin{array}{l}\text { As early as } \\
\text { possible to } \\
\text { obtain } \\
\text { prospective } \\
\text { advice }\end{array}$ & $\begin{array}{l}\text { As early as } \\
\text { possible to } \\
\text { obtain } \\
\text { prospective } \\
\text { advice }\end{array}$ \\
\hline How to submit/contact & $\begin{array}{l}\text { - Initiation request to } \\
\text { FDA: contact via email } \\
\text { FDA-initiated invitation } \\
\text { to submit a Letter of } \\
\text { Intent: Electronic } \\
\text { submission } \\
\text { accompanied by paper } \\
\text { cover letter to Central } \\
\text { Document Room (see }\end{array}$ & $\begin{array}{l}\text { - Initiation request to } \\
\text { EMA: contact via } \\
\text { email: Qualification } \\
\text { - EMA-initiated } \\
\text { invitation to submit a } \\
\text { Letter of Intent: } \\
\text { Electronic submission } \\
\text { accompanied by paper } \\
\text { cover letter to Central }\end{array}$ & As per US FDA & As per US FDA \\
\hline
\end{tabular}




\begin{tabular}{|c|c|c|c|c|}
\hline & $\begin{array}{l}\text { FDA Website for } \\
\text { address) } \\
\text { - Contact information } \\
\text { for the three } \\
\text { Qualification Programs } \\
\text { is available on FDA } \\
\text { Website * }\end{array}$ & $\begin{array}{l}\text { Document Room (see } \\
\text { EMA Website for } \\
\text { address) }\end{array}$ & & \\
\hline Fees & None & $\begin{array}{l}\text { Same fee reductions as } \\
\text { in scientific advice for } \\
\text { paediatric (free), orphan } \\
\text { conditions and SMEs } \\
\text { (small and medium- } \\
\text { sized enterprises } \\
(10 \%) \text { ). }\end{array}$ & None & None \\
\hline Length of procedure & $\begin{array}{l}\text { Not defined } \\
\text { (dependent upon } \\
\text { complexity of } \\
\text { submission) }\end{array}$ & $\begin{array}{l}\text { Qualification Advice: } \\
100 \text { days Qualification } \\
\text { opinion: } 190 \text { (dependent } \\
\text { upon complexity of } \\
\text { submission) }\end{array}$ & Not defined & Not defined \\
\hline Follow-up & $\begin{array}{l}\text { Once a qualification } \\
\text { recommendation has } \\
\text { been made publicly } \\
\text { available, the } \\
\text { qualification } \\
\text { recommendation may } \\
\text { be revised as new } \\
\text { scientific evidence } \\
\text { becomes available. }\end{array}$ & $\begin{array}{l}\text { Follow-up Qualification } \\
\text { Advice: } 100 \text { days } \\
\text { Qualification opinion: } \\
190 \text { (dependent upon } \\
\text { complexity of } \\
\text { submission }\end{array}$ & Not Mentioned & Not Mentioned \\
\hline
\end{tabular}

\section{Conclusion}

The regulated countries like USA and Europe have understood the importance of qualification of drug development tools. In semi regulated markets like India, still there is a lot to be done. In India there are no stringent regulations for qualifying the drug development tools. If the tools that aids in the drug development is specified and guidelines regarding qualification is recommended then the duplication efforts will be reduced, it will facilitate the drug development process with the help of qualified tools and overall public safety will be increased.

\section{Acknowledgments}

The authors are thankful to Dr. K. Pundarikakshudu, Director of L. J. Institute of Pharmacy, Ahmedabad, India for providing all the facilities and encouragement to carry out the work and also for providing support and knowledge.

\section{Conflict of interest}

The authors declare that there are no conflicts of interest.

\section{References}

1. U.S. Food and Drug Administration. Drug Development Tool Qualification Programme [Internet]. FDA; 2018 [Cited 2018 Jan 04] Available from:

https://www.fda.gov/Drugs/DevelopmentApprovalPr ocess/DrugDevelopmentToolsQualificationProgram/

2. Strimbu K, Tavel JA. What are Biomarkers?, Current opinion in HIV and AIDS [Internet]. 2010 [Cited 2018 Jan 04]; 5(6). Available from:
https://www.ncbi.nlm.nih.gov/pmc/articles/PMC3078 627/

3. Ed Miseta, What You Need To Know About FDA's Clinical Outcome Assessment Compendium [Internet]. Clinical leader; 2016 Feb 08 [Cited 2018 Jan 06].Available from:

www.clinicalleader.com/doc/what-you-need-toknow-about-fda-s-clinical-outcome-assessmentcompendium-0001

4. Committee on Animal Models for Assessing Counter measures to Bioterrorism Agents [Internet]. The National Academy Press; 2011 [Cited 2018 Jan 08]. Available from:

https://www.nap.edu/catalog/13233/animal-modelsfor-assessing-countermeasures-to-bioterrorism-agents

5. U.S. Department of Health and Human Services, Food and Drug Administration. Guidelines on Qualification Process of Drug Development Tools [Internet]. Center for Drug Evaluation and Research (CDER); 2014 Jan [Cited 2018 Jan 08]. Available from:

https:/www.fda.gov/downloads/drugs/guidances/ucm 230597.pdf

6. EMA. Qualification of novel methodologies for drug development: guidance to applicants [Internet]. EMEA; 2009 [Cited 2018 Jan 08]. Available from: http://www.ema.europa.eu/docs/en_GB/document_lib rary/Regulatory_and_procedural_guideline/2009/10/ WC500004201.pdf

7. EMA. Reflection paper on methodological issues associated with pharmacogenomic biomarkers in relation to clinical development and patient selection [Internet]. EMEA; 2015 [Cited 2018 Jan 09]. Available from: 
http://www.ema.europa.eu/docs/en_GB/document_lib rary/Scientific_guideline/2015/11/WC500196800.pdf

8. EMA. Reflection paper on co-development of pharmacogenomic biomarkers and Assays in the context of drug development [Internet]. EMEA; 2010 [Cited 2018 Jan 09]. Available from:

http://www.ema.europa.eu/docs/en_GB/document_lib rary/Scientific_guideline/2010/07/WC500094445.pdf

9. EMA. Guideline on non-clinical local tolerance testing of medicinal products [Internet]. EMEA; 2015 [Cited 2018 Jan 10]. Available from: http://www.ema.europa.eu/docs/en_GB/document_lib rary/Scientific_guideline/2015/11/WC500197321.pdf

10. Nieto-Gutierrez M. Non-clinical Assessment Requirements. Safety and Efficacy of Medicines/ Human Medicines Development and Evaluation [Internet]. EMEA; 2011 [Cited 2018 Jan 10] Available from:

http://www.ema.europa.eu/docs/en_GB/document_lib rary/Presentation/2011/06/WC500107868.pdf

11. ICH E 16: Genomic Biomarkers Related to Drug Response: Context, Structure and Format of Qualification Submissions [Internet].EMEA; 2009 [Cited 2018 Jan 10]. Available from: http://www.ema.europa.eu/docs/en_GB/document_lib rary/Scientific_guideline/2009/09/WC500002881.pdf

12. Technical Guidance on Development of In Vitro Companion Diagnostics and Corresponding therapeutic Products [Internet]. [Cited 2018 Jan 10]. Available from:

file:///H:/data0/guidance-biomarker,\%20JAPAN000 153149.pdf

13. Notification on Approval Application for In Vitro Companion Diagnostics and Corresponding Therapeutic Products [Internet]. PMDA; 2013 July 01[Cited 2018 Jan 10]. Available from: https://www.pmda.go.jp/files/000153914.pdf

14. Kagiyama N, et.al. Japanese Guidelines \& Regulations for Scientific \& Ethical Animal Experimentation [Internet]. Japan: 2006 [Cited 2018 Jan 11]. Available from: https://www.aaalac.org/intlRefs/IntRegs/Japan/Privat e\%20site/Japanese_Guidelines.pdf

15. Omoe H. Recent Trends in Animal experimentation in Japan - On the Revision and Implementation of the Law for the Humane Treatment and Management of animals. [Internet]. Life Science Research Unit; 2006 Oct [Cited 2018 Jan 11]. Available from: http://data.nistep.go.jp/dspace/bitstream/11035/2728/ 1/NISTEP-STT021E-13.pdf

16. Discussion paper. Workshop on Policy Issues for the Development and Use of Biomarkers in Health [Internet]. OECD; 2008 [Cited 2018 Jan 11].

Available from: https://www.oecd.org/health/biotech/49023036.pdf

17. ICMR. Inserm Development of Biomarkers for CVD \& Diabetes [Internet]. ICMR; 2007 [Cited 2018 Jan 12]. Available from: www.icmr.nic.in/biomarkers/report.pdf

18. CPCSEA Guidelines For Laboratory Animal Facility, Committee for the Purpose of Control and Supervision on Experiments on Animals. Indian
Journal of Pharmacology [Internet].2003 [Cited 2018 Jan 12]; 35:257-74. Available from: http://medind.nic.in/ibi/t03/i4/ibit03i4p257.pdf 